\title{
Ionospheric Anomalies before/after the 1960 Agadir Earthquake
}

\author{
Enoch Oluwaseun Elemo \\ Centre for Atmospheric Research, Anyigba, Nigeria \\ Email: enochelemo@yahoo.com
}

Received 3 November 2014; revised 6 December 2014; accepted 26 December 2014

Copyright (C) 2014 by author and OALib.

This work is licensed under the Creative Commons Attribution International License (CC BY). http://creativecommons.org/licenses/by/4.0/

(c) (i) Open Access

\section{Abstract}

This paper focuses on the ionospheric anomalies observed in the F2 layer at Tortosa in Ebre Observatory $\left(40.8^{\circ} \mathrm{N}, 0.49^{\circ} \mathrm{E}\right)$, before and after a seismic event in Morocco (Agadir). The data on optimal frequency of F2 layer (fOF2) were acquired using ground based ionosonde. The medianbased statistical technique was applied to the data to examine the possible relationship between the earthquake displacement field and the variation of the f0F2 in the ionosphere. The results point to a variation characterized by absence of fOF 2 values over four days before the earthquake and continue for almost three days after the day of earthquake. The diurnal monthly median of the f0F2 values also revealed anomalous which has been considered as supporting evidence for the observed correlation.

\section{Keywords}

Ionospheric Anomalies, Seismic Event at Agadir, Ionosonde, Ebre Observatory

Subject Areas: Atmospheric Sciences, Geophysics

\section{Introduction}

Earthquake precursors can be said to be difficult to recognize because of the complexity of mechanical deformation of blocks in the Earth's crust, the various types of mechanisms of the earthquake itself, the lack of extensive knowledge of geophysical characteristics of seismicity together with poor understanding of the geochemical monitoring in most areas of the globe. Notable among the associated phenomena with earthquakes processes are the anomalous change of intensity of electric field [1]-[4], the anomalous propagation of signals (ULF, VLF and HF) as expressed by [5], an increase of spike type noises [6] and combination of those phenomena [7]. It is also well-known that ionospheric variations are strongly related to the 11-year solar cycle [8].

Solar activities control directly or indirectly phenomena that affect ionospheric variability such as ionospheric storms, polar cap absorption (PCA), travelling ionospheric disturbances, and magnetic storms. Moreover, there 
are fluctuations in the ionosphere electron density which cannot be attributed to any one of the aforementioned sources, and are therefore called geophysical noise [9]. With the chaotic and nonlinear behavior of the ionosphere, it is reasonable to assume that the foF2 measurements over a given period for a signal consist of linear, nonlinear and non-stationary components. Recently, electromagnetic phenomena in the ionosphere associated with seismic activity have been extensively discussed [10]-[12]. [13] observed that the VLF perturbation events appeared as transient oscillations with 5 - 10 days period and was initiated a few days before a large earthquake and decaying over a few days or weeks after it. [8] noticed that before the earthquakes, the distribution of the perturbed plasma at the ionospheric F2 layer around the seismic active zone produced regions with enhanced or decreased concentration. [14] [15] utilized the ionospheric plasma frequency recorded by a local ionosonde between 1994 and 1999, and found out that the critical frequency of the F2 layer (foF2) significantly decreased few days prior to most of the earthquakes $(\mathrm{M}>6)$ in the Taiwan area. [8], however, discussed the decrease of foF2 in the morning hours 1 - 5 days before strong earth quakes too.

The seismic event designated here as the 1960 Agadir earthquake took place on Monday, February 29, 1960, at 23:47 hrs local time. It is considered as the most destructive and deadliest earthquake in Moroccan history with a magnitude of $5.7 \mathrm{Mw}$, killing around 15,000 people (about a third of the city's population of the time) and injuring another 12,000. At least 35,000 people were left homeless. Despite its moderate magnitude, the earthquake's shallow-focus and proximity to the major city of Agadir made it very destructive. It is the most destructive "moderate" quake (magnitude less than 6 ) in the $20^{\text {th }}$ Century.

\section{Data and Analysis Technique}

The majority of the methods used in seismo-ionospheric coupling studies are statistical in character, where some ionospheric parameters (dealing usually with foF2 or TEC) are evaluated for a period both before and after the earthquake. The main objective in all of these studies is to identify a significant deviation of the examined parameter from its median value prior to the seismic event. The f0F2 values obtained using an ionosonde in Tortosa, between $14^{\text {th }}$ of February to $14^{\text {th }}$ March 1960 were downloaded from the web site of NOAA Space Environment Center. The data of dst index and Kp index of the same period were obtained from WDC web site at Kyoto, Japan.

The foF2 data is plotted as Figure 1. The hourly median foF2 values of the month of January, February,

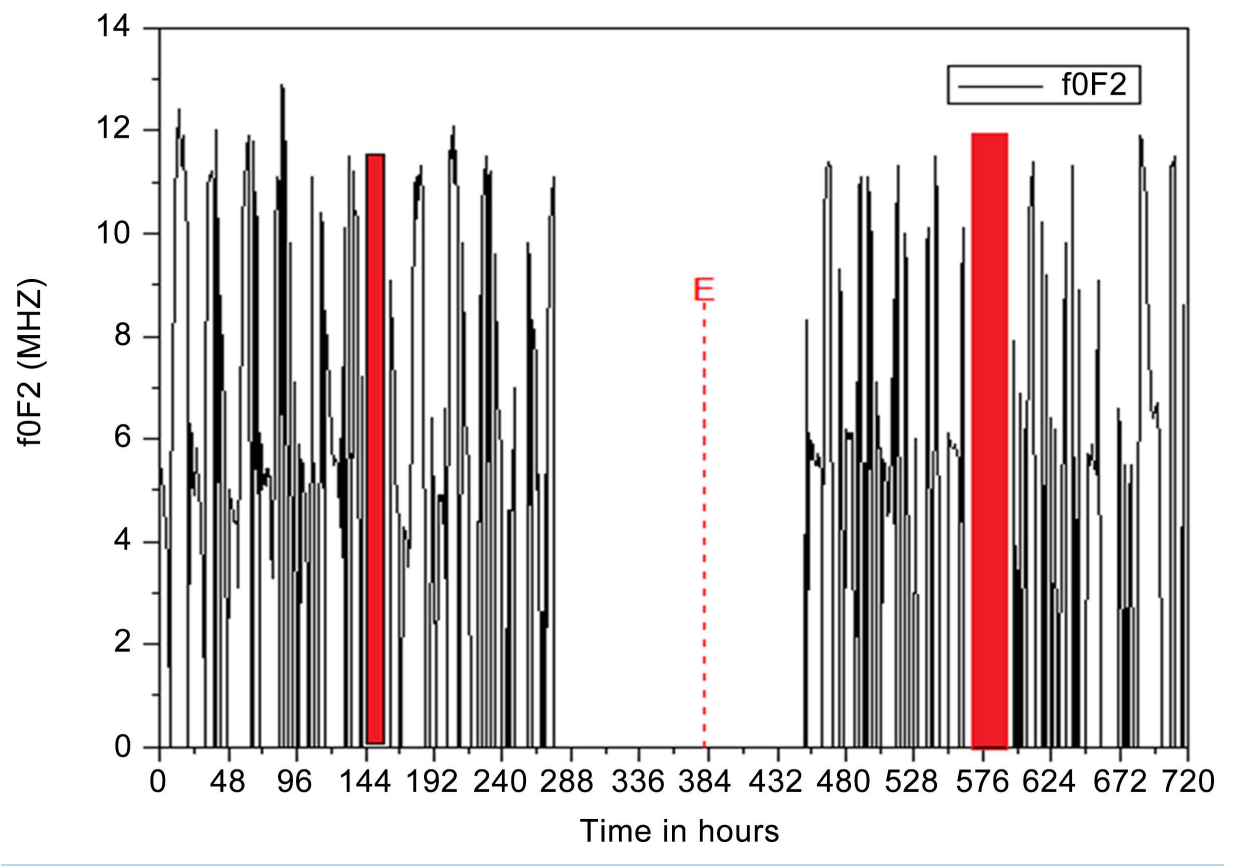

Figure 1. Variation of foF2 values between $14^{\text {th }}$ February and $14^{\text {th }}$ March 1960 (in hours). The dashed line with letter $\mathrm{E}$ indicates time of occurrence of earthquake. The red gaps in the graph shows other time the f0F2 were absent. 
March and April are plotted in Figure 2. Figure 3 shows the corresponding dst and Kp index of the same period so as to further confirm whether the perturbations noticed in the foF2 value is related to ionospheric condition around that time. Moreover, Figure 4 also shows the contour map of hourly median.
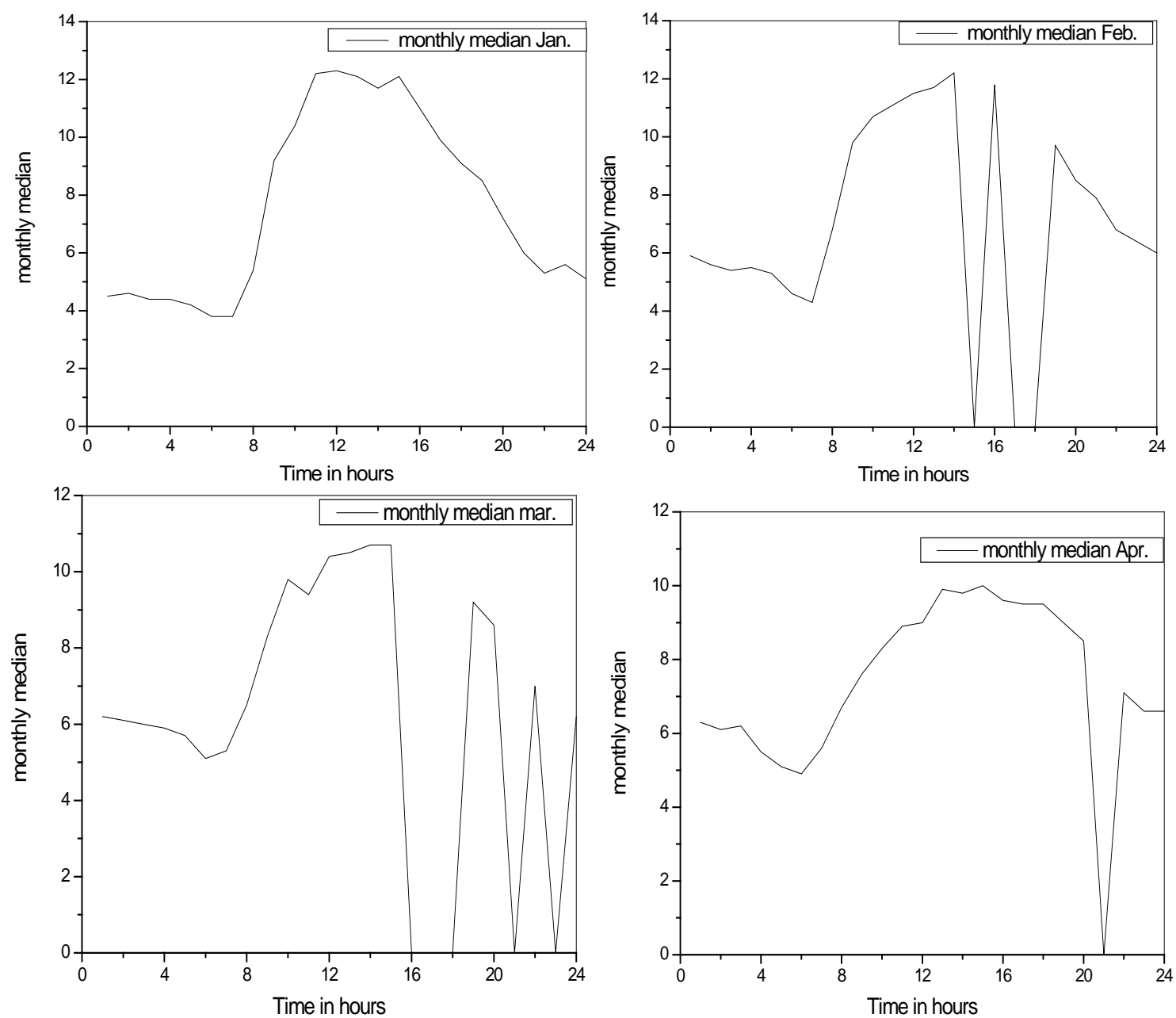

Figure 2. Monthly median of the f0F2 data for the month of January, February, March and April 1960.

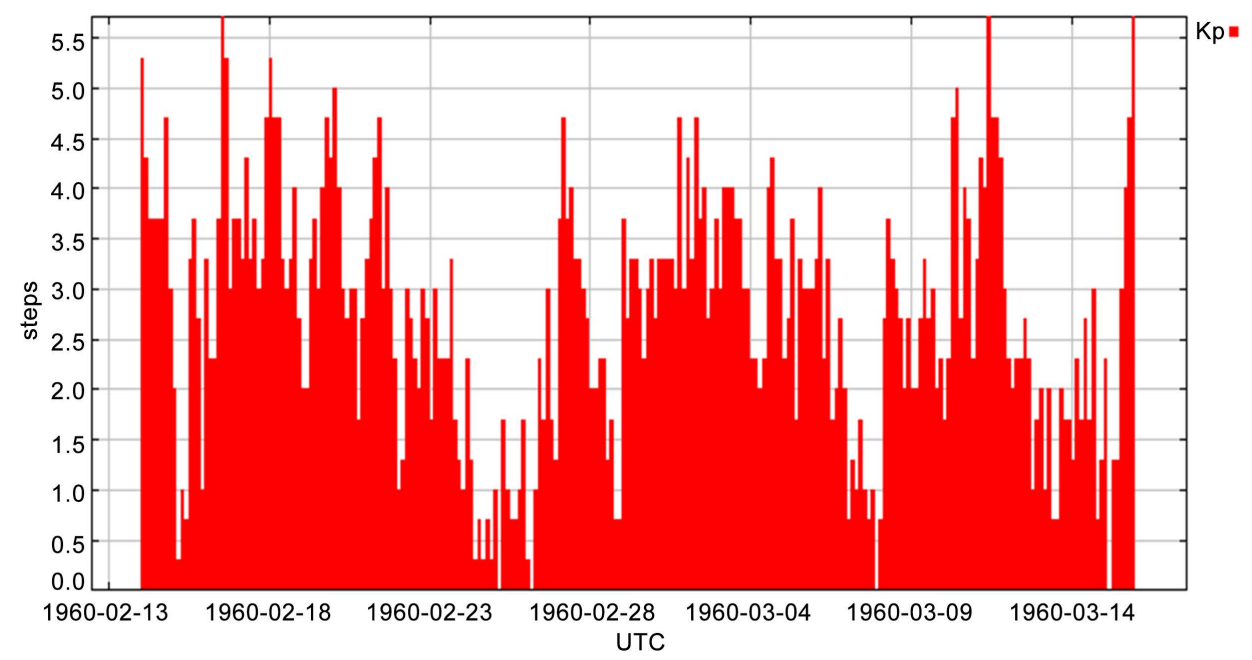

(a) 


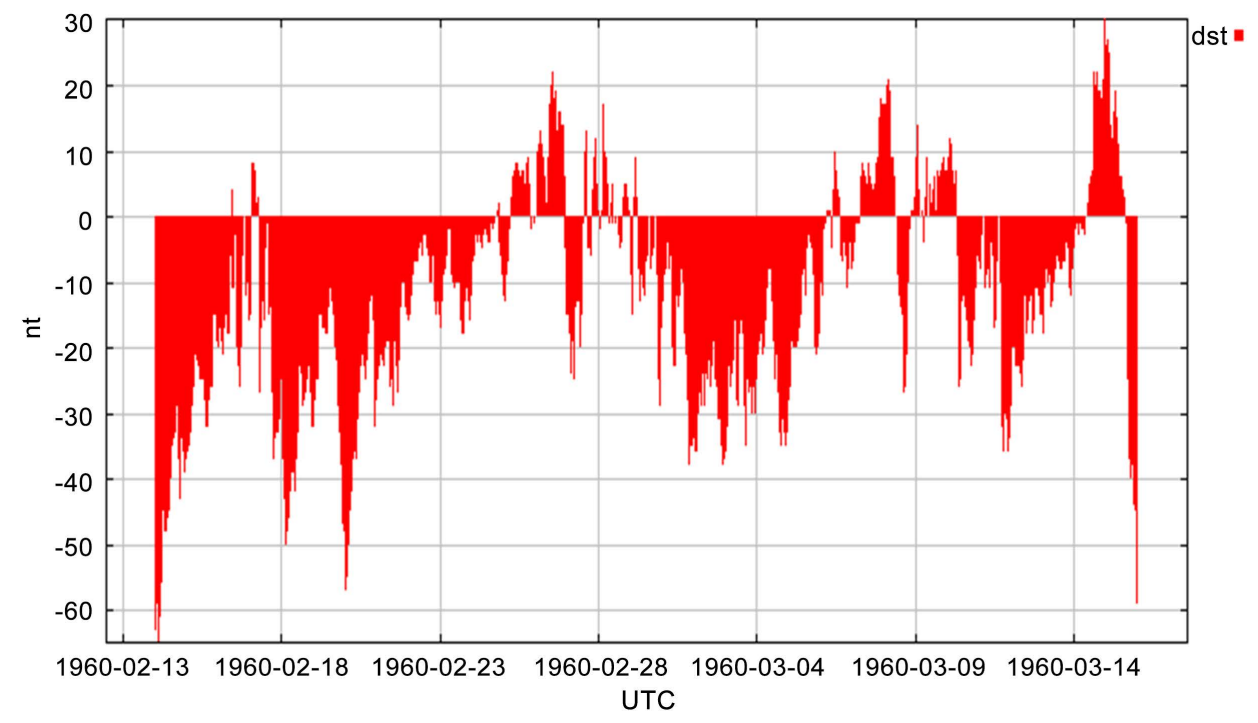

(b)

Figure 3. The Kp and dst index for the period of February $14^{\text {th }}$ and March $14^{\text {th }} 1960$.

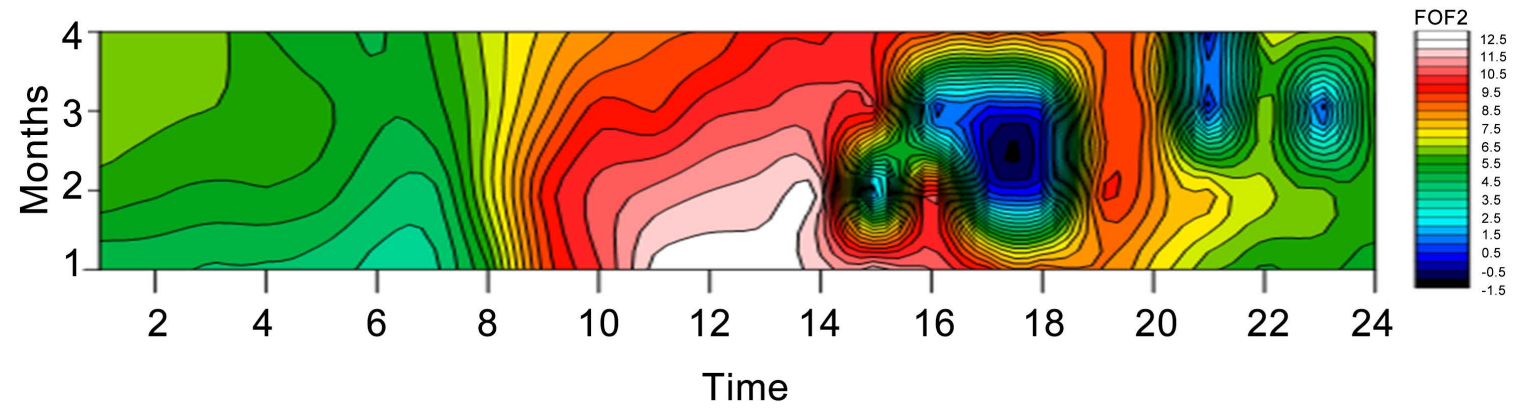

Figure 4. Contour map of the monthly median values of f0F2 from january to April, 1960 (where 1 to 4 represent January to April).

\section{Result}

It is clear from Figure 1 that the f0F2 values are absent over four days prior to the day of the earthquake and remained the same until almost three days after the earthquake. Moreover, f0F2 were also absent at two other times as shown by the same graph. While Figure 2 not only shows the diurnal nature of hourly median as expected, but also that the hourly median values peaks at roughly around 13:00 hrs or 14:00 hrs in the months studied. However, a particularly different variation was noticed in February and March. Both months showed a different variation when compared to both January and April, from 15:00 hrs till the 24:00 hrs. The presence of this kind of variation clearly shows the occurrence of certain activities in the two months. While both months (February and March) exhibited that occurrence around the same time, the actual trend of the variation is different. However, the variation returned back nearly to the usual one in the month of April. Figure 3 illustrates the $\mathrm{Kp}$ and the dst index for the same period (30 days) revealing the non existence of geomagnetic activities during this period and most especially during the days where the values were absent $\left(24^{\text {th }}\right.$ of February to $3^{\text {rd }}$ of March 1960). Figure 4 however shows the contour map of hourly median values of the f0F2 for the months of January to April (represented in the graph by 1 to 4). This map shows the steady rise in values of f0F2 from roughly 08:00 hrs in all the months. However, February and March had a different situation between 16:00 hrs and 18:00 hrs as seen in the map.

As can be verified from the summary provided in Table 1 the distance from the station to the epicenter of the earthquake is around $1400 \mathrm{~km}$. This is much higher than the values usually reported for the dimensions of earthquake displacement fields in the literature. 
Table 1. Characteristics of Agadir earthquake.

\begin{tabular}{|cccccccc}
\hline Agadir town & Epicenter & Station & $\begin{array}{c}\text { Magnitude of } \\
\text { earthquake }\end{array}$ & Duration & $\begin{array}{c}\text { Focal depth } \\
\text { (km) }\end{array}$ & $\begin{array}{c}\text { Time of } \\
\text { earthquake }\end{array}$ & $\begin{array}{c}\text { Distance of the } \\
\text { station to epicenter }\end{array}$ \\
\hline $30.4^{\circ} \mathrm{N}, 9.6^{\circ} \mathrm{W}$ & $30.5^{\circ} \mathrm{N}, 9.6^{\circ} \mathrm{W}$ & $40.8^{\circ} \mathrm{N}, 0.49^{\circ} \mathrm{E}$ & $5.7 \mathrm{M}_{\mathrm{W}}$ & 15 secs & $2-3$ & $23: 47$ local time & $1400.7 \mathrm{~km}$ \\
\hline
\end{tabular}

\section{Conclusion}

This is probably the first work done using f0F2 as an ionospheric precursor on Agadir earthquake. The results obtained point to the presence of a unique ionospheric perturbation over the Tortosa station several days before and after the main shock of earthquake that occurred in Agadir. The perturbation is characterized by the absence of f0F2 well over four (4) days before and maintains that trend for almost three (3) days after the earthquake. The fact that the Ebre observatory was not reported to have any problems in data acquisition systems during this period (7 days at ago) to justify the lack of observational data clearly shows the cause to be of seismogenic origin. Whereas, the other two times that such incident occurred was for only 19 hrs and 34 hrs, but had no occurrence of earthquake. [16] in their recent work showed that the occurrences of earthquakes did not always coincide with gaps in ionosonde observations. It is possible that such ionospheric disturbances are related to the action of upward propagating electric field which was produced due to tectonic movements which enable electric charge to appear at the surface of the Earth and modify the currents in atmosphere-ionosphere system. According to seismo-ionospheric responses arising during the earthquake preparation stage, it is known that the modification of the anomaly associated with seismic activity has various characteristics that were described earlier and in this case observed well over four (4) days before and continue for almost another three (3) days after the earthquake. In the course of the preparatory stage of earthquake, there was a penetration of abnormal electric field of seismogenic origin into the ionospheric heights which strengthened or weakened the variation of foF2 [7]. The abnormal electric field moderates the $\mathbf{E} \times \mathbf{B}$ drift process and causes subsequent spatial distribution of electron concentration. The depression in f0F2 values noticed in this case may be attributed to the negative direction of the electric fields through $\mathbf{E} \times \mathbf{B}$ drift process over the epicenter of the earthquake, which may move towards or away from Agadir depending upon the negative direction of electric fields or neutral winds. However, it has been observed that in this region the Plasma bubbles are much deeper and occur more frequently than bubbles observed in any other longitudinal sector [17]. It was also reported that the depletions in the African region rose to high altitudes (up to $1000+\mathrm{km}$ ) more frequently compared to other longitudes [18]. This may be accountable for the reason why the seismo-ionospheric effect was still felt in spite of the distance between the station and the epicenter. The fact that the variation in the hourly median values in the month of February experienced a clearly visible and unique variation towards the evening-time and at night-time shows that the variation will most likely be of seismic sources.

\section{Acknowledgements}

I acknowledge the National Oceanic Atmospheric Administration (NOAA) website: (http://www.wdc.stp.rl.ac.uk) for providing the data. I can't but appreciate the great efforts done by the referee of this work in making the paper much better and well grounded. Thanks a lot.

\section{References}

[1] Fraser-Smith, A.C., Bernardi, A., McGill, P.R., Ladd, M.E., Helliwell, R.A. and Villard Jr., O.G. (1990) Low-Frequency Magnetic Measurements near the Epicenter of the 7.1 Loma Prieta Earthquake. Geophysical Research Letters, 17, 1465-1468. http://dx.doi.org/10.1029/GL017i009p01465

[2] Fujinawa, Y., Kumagai, T. and Takahashi, K. (1992) A Study of Anomalous Underground Electric-Field Variations Associated with a Volcanic Eruption. Geophysical Research Letters, 19, 9-12. http://dx.doi.org/10.1029/91GL02822

[3] Gokhberg, M.B., Morgounov, V.A., Yoshino, T. and Tomizawa, I. (1982) Experimental Measurement of Electromagnetic Emissions Possibly Related to Earthquakes in Japan. Journal of Geophysical Research: Solid Earth (1978-2012), 87, 7824-7828. http://dx.doi.org/10.1029/JB087iB09p07824

[4] Molchanov, O.A., Kopytenko, Yu.A., Voronov, P.M., Kopytenko, E.A., Matiashvili, T.G. and Bernardi, A. (1992) Results of ULF Magnetic Field Measurements near the Epicenters of the Spitak $\left(M_{s}=6.9\right)$ and Loma Prieta $\left(M_{s}=7.1\right)$ Earthquakes: Comparative Analysis. Geophysical Research Letters, 19, 1495-1498. 
http://dx.doi.org/10.1029/92GL01152

[5] Hayakawa, M., Yoshino, T. and Morgounov, V.A. (1993) On the Possible Influence of Seismic Activity on the Propagation of Magnetospheric Whistlers at Low Latitudes. Physics of the Earth and Planetary Interiors, 77, 97-108. http://dx.doi.org/10.1016/0031-9201(93)90036-9

[6] Oike, K. and Ogawa, T. (1986) Electromagnetic Radiations from Shallow Earthquakes Observed in the LF Range. Journal of Geomagnetism and Geoelectricity, 38.

[7] Pulinets, S.A. and Boyarchuk, K.A. (2004) Ionospheric Precursors of Earthquakes. Springer, Berlin, 315 p.

[8] Pulinets, S.A. (1998) Seismic Activity as a Source of the Ionospheric Variability. Advances in Space Research, 22, 903-906. http://dx.doi.org/10.1016/S0273-1177(98)00121-5

[9] Davies, K. (1990) Ionospheric Radio. Peter Peregrinus Ltd., London. http://dx.doi.org/10.1049/PBEW031E

[10] Freund, F. (1999) Time-Resolute Study of Charge Generation and Propagation in Igneous Rocks. Journal of Geophysical Research, 104.

[11] Hayakawa, M. (1999) Atmospheric and Ionospheric Electromagnetic Phenomena Associated with Earthquakes. Terra Scientific Publishing Company, Tokyo.

[12] Pulinets, S.A., Legen'ka, A.D. and Alekeseev, V.A. (1994) Pre-Earthquake Ionospheric Effects and Their Possible Mechanisms, in Dusty and Dirty Plasmas, Noise and Chaos in Space and in Laboratory. Plenum Publishing, New York, 545-557. http://dx.doi.org/10.1007/978-1-4615-1829-7_46

[13] Molchanov, O.V. and Hayakawa, M. (1998) Sub-Ionospheric VLF Signal Pertubations Possibly Related to the Earthquake. Journal of Geophysical Research: Space Physics (1978-2012), 103, 17489-17504. http://dx.doi.org/10.1029/98JA00999

[14] Pulinets, S.A., Boyarchuk, K.A., Khegai, V.V., Kim, V.P. and Lomonosov, A.M. (2000) Quasielectrostatic Model of Atmosphere-Thermosphere-Ionosphere Coupling. Advances in Space Research, 26, 1209-1212. http://dx.doi.org/10.1016/S0273-1177(99)01223-5

[15] Pulinets, S., Kotsarenko, A.N. and Ciraolo, L. (2007) Special Case of Ionospheric Day-to-Day Variability Associated with Earthquake Preparation. Advances in Space Research, 39, 970-977. http://dx.doi.org/10.1016/j.asr.2006.04.032

[16] Pulinets, S. and Davidenko, D. (2014) Ionospheric Precursors of Earthquakes and Global Electric Circuit. Advances in Space Research, 53, 709-723. http://dx.doi.org/10.1016/j.asr.2013.12.035

[17] Hei, M.A., Heelis, R.A. and McClure, J.P. (2005) Seasonal and Longitudinal Variation of Large Scale Topside Equatorial Plasma Depletions. Journal of Geophysical Research, 110.

[18] Burke, W.J., Gentile, L.C., Huang, C.Y., Valladares, C.E. and Su, S.Y. (2004) Longitudinal Variability of Equatorial Plasma Bubbles Observed by DMSP and ROCSAT-1. Journal of Geophysical Research, 109. 